\title{
Los refugiados de la pobreza y sus causas de origen: responsabilidades y deberes de los países menos desarrollados ante la injusticia global $^{1}$
}

\section{Refugees from Poverty and their Root Causes: Duties and Actions from the Least Developed Countries at the Global Injustice}

\author{
Guillermo Andrés Duque Silva² \\ Universidad del Valle (Colombia) \\ ORCID: https://orcid.org/0000-0002-0361-0571
}

Recibido: 29-06-2021

Aceptado: 16-09-2021

\section{Resumen}

Este artículo analiza una teoría inédita sobre el origen de las injusticias globales que considera a los países en desarrollo como unidades ontológicas éticamente responsables. Los estudios de caso empíricos atañen a las relaciones entre empresas multinacionales de Estados desarrollados y Estados de América Latina. Estos casos se analizan a partir de una metodología cualitativa de filosofía política aplicada y corresponden a doce instancias de injusticia juzgadas por la Corte Interamericana de Derechos Humanos entre 1980 y 2014 vinculadas a

\footnotetext{
${ }^{1}$ Este artículo se ha elaborado en el marco del Proyecto Integración, Derechos Humanos y Ciudadanía Global, de la Convocatoria Pública de Subvenciones para la realización de Proyectos de Investigación en materia de Ciudadanía Global y Cooperación Internacional al Desarrollo 2020, del Ayuntamiento de Madrid con la Universidad Rey Juan Carlos.

${ }^{2}$ (guillermo.duque@urjc.es) Profesor e investigador en la Universidad Rey Juan Carlos. Ph.D. en Ciencias Sociales y Jurídicas, Universidad Rey Juan Carlos y Ph.D. en Ciudadanía y Derechos Humanos, Universitat de Barcelona. Investigador Postdoctoral de la Convocatoria de Atracción de Talento de la Comunidad de Madrid y el FSE de la UE. Autor de libros como: En ausencia del enemigo: Carl Schmitt en el siglo XXI, coautor de obras como: La Digitalización de la Colombia rural y Democracia Estado e Ideología y de artículos de alto impacto como: Agamben tiene razón: COVID 19 y estado de excepción permanente.
} 
proyectos mega-empresariales. El artículo concluye que las distorsiones en una emergente Ética de la interdependencia global, como el actuar de mala fe de los gobiernos de los países en desarrollo, explica en buena parte los orígenes de la injusta distribución global de la riqueza y de los refugiados económicos que ella produce.

Palabras-clave: Relaciones Internacionales, justicia, cosmopolitismo, Derechos Humanos, ética, derecho internacional, refugiados.

\begin{abstract}
This paper analyzes an unpublished theory about the origin of global injustices that consider developing countries ethically responsible ontological units. The empirical case studies concern the relationships between multinational companies from developed states and Latin American states. These cases are analyzed based on a qualitative methodology of applied political philosophy and correspond to twelve instances of injustice judged by the Inter-American Court of Human Rights between 1980 and 2014. The article concludes that the distortions in an emerging Ethics of the interdependence of the States, as the acting in bad faith of the governments of developing countries, largely explains the origins of the unfair global distribution of wealth and the economic refugees that it produces.
\end{abstract}

Keywords: International Relations, justice, cosmopolitanism, Human Rights, ethics, international law, refugees.

\title{
Introducción
}

Entre 2015 y 2021 cerca de 3.5 millones de inmigrantes se han asentado en las sociedades europeas en busca de protección internacional ${ }^{3}$. A este fenómeno se le suele llamar Crisis de los refugiados y tuvo como punto de partida la inmigración de civiles que huían, principalmente, del conflicto sirio. El arribo de solicitantes de protección internacional en los últimos cinco años no solo ha crecido de forma vertiginosa, sino que ha cambiado en cuanto a su composición; ha variado particularmente la lista de países predominantes tanto de origen, como de destino. De hecho, la diversidad de Estados de origen de la inmigración demandante de protección internacional en los últimos tres años demuestra que los conflictos armados ya no son la principal causa de este tipo de inmigración: las crisis institucionales y económicas juegan un papel

\footnotetext{
${ }^{3}$ Parlamento Europeo, ¿Es Europa hospitalaria? Recuperado de: https://www.europarl.europa.eu/ infographic/welcoming-europe/index_es.html\#filter=, 2019. (último acceso: 10.05.2021).
} 
preponderante en la decisión de buscar de refugio en el exterior. Un ejemplo de los cambios que ha tenido la denominada Crisis de los refugiados es el periodo 2019-2021 que se ha caracterizado por un crecimiento sin precedentes de la inmigración venezolana, colombiana, hondureña, salvadoreña y nicaragüense solicitante de asilo en Europa, particularmente en España. En 2019 el número de solicitantes de protección internacional en España, proveniente de estos cinco países, se multiplicó por 45 respecto a 2012, lo que ha desbordado el sistema de acogida español y ha convertido el aeropuerto Adolfo Suárez Barajas de Madrid, en la principal frontera de Europa ${ }^{4}$.

Se suele replicar que entre los solicitantes de protección internacional de esta última etapa se esconden inmigrantes económicos que buscan, "simplemente", mejorar sus condiciones materiales de vida sin ser propiamente perseguidos políticos u otro tipo de víctima de los establecidos en el Estatuto de Ginebra. Si esto es cierto, el resultado no debería ser cuestionar moralmente el uso indebido de una figura jurídica de protección internacional de los derechos humanos, sino preguntarnos qué está sucediendo en los países de origen para que esa vía constituya la única opción de supervivencia para millones de personas que migran, sin cesar, a Europa. Es decir, ante la afluencia creciente de inmigrantes, perseguidos o no, debemos examinar si merece la pena distinguir entre las personas que emigran de un país en conflicto, hostigados por cuestiones de género o por preferencias políticas o religiosas para proteger su vida; de aquellas que huyen de la pobreza extrema, también, para preservar su vida. Mientras que la opción por mantener esta distinción ha justificado la salida -facilista-de rechazar el $96 \%$ de las solicitudes de asilo que se presentan en Europa ${ }^{5}$; una respuesta negativa a dicha diferenciación entre inmigrantes económicos y refugiados enfocaría nuestra mirada en un análisis más amplio de la crisis migratoria que ahondaría en sus dimensiones estructurales.

Empecemos por recordar que las personas que llegan a pedir refugio a Europa usualmente cuentan con recursos para trasladarse en avión o al menos para pagar a las bandas de contrabandistas que les transportan ilegalmente, pertenecen a las clases medias o altas de sus países; esto indica que detrás de ellos se oculta un problema de mayor magnitud: el sufrimiento encarnado por aquellos que se quedan en los países de origen, dado que, simplemente, no pueden costearse un viaje en busca de refugio. Esas personas, las que se quedan, componen un grupo social más vulnerable que los propios refugiados y solicitantes de asilo: son el eslabón más frágil que produce el capitalismo hoy. Desde esa óptica, la crisis de los refugiados ha servido para exhibir en

\footnotetext{
${ }^{4}$ Eurostat Statistics Explained. Estadísticas de asilo. Recuperado de: https:/ec.europa.eu/eurostat/ statistics-explained/pdfscache/62527.pdf, 2019. (último acceso: 10.05.2021).

${ }^{5}$ El País.Com, España se sitúa ya a la cola de la UE en las concesiones de asilo. Madrid, El País.com (04/02/2020). Recuperado de: https://elpais.com/politica/2020/02/04/actualidad/1580821771 393934. html, 2020, (último acceso: 10.05.2021).
}

Araucaria. Revista Iberoamericana de Filosofí, Política, Humanidades y Relaciones Internacionales, año $23, \mathrm{n}^{\circ} 48$. Tercer cuatrimestre de 2021. Pp. 551-576. ISSN 1575-6823 e-ISSN 2340-2199 https://dx.doi.org/10.12795/araucaria.2021.i48.25 
suelo europeo, no solo las necesidades de quienes llegan, sino el sufrimiento silencioso de aquellos que se quedan. Los refugiados, en ese sentido, son una pequeña muestra poblacional de sociedades enteras que se encuentran condenadas a vivir al margen del desarrollo capitalista. Si al mirar a los ojos del refugiado podemos, además, notar la presencia ausente de aquellos que no pueden viajar, estamos reconociendo nuestra capacidad moral de apuntar al trasfondo de la crisis migratoria.

Con esa perspectiva en mente, la crisis de los refugiados o actual crisis migratoria se sublima al nivel de una manifestación de un fenómeno mayor, que merece la pena que analicemos: la absoluta pobreza que produce el capitalismo en las sociedades de origen de la inmigración. El filósofo alemán Thomas Pogge, que ha impulsado una investigación en esa dirección, no solo afirma que la crisis migratoria que vive Europa y Estados Unidos no puede desligarse de los efectos perversos del sistema económico capitalista, sino que profundiza en su argumento para indicar que los países desarrollados son moralmente responsables por dichos daños, pues han sido los artífices de este orden global injusto y los encargados de sostener un conjunto de reglas de competencia internacional que son desleales con los Estados más débiles.

Desde ese enfoque no debe sorprender entonces que la crisis migratoria encuentre sus raíces en las carencias que viven los 7.4 millardos de personas pobres en el mundo ${ }^{6}$. Es decir, que una buena parte de los refugiados que viajan a Europa lo hacen buscando salir del conjunto de 1300 millones de personas que hoy viven en la pobreza multidimensional ${ }^{7}$. Los refugiados son la punta de un iceberg que esconde en sus bases, por ejemplo, a los 800 millones de personas que hoy, según la FAO, sufren de desnutrición crónica; son la cara visible en Europa, por un lado, de los 2000 millones de personas que no cuentan con acceso a medicinas esenciales $\mathrm{y}$, por otro lado, de los 750 millones que no tienen acceso al agua potable ${ }^{8}$. Detrás de los 3,5 millones de refugiados que hay en Europa, se encuentran 1000 millones de personas que no cuentan con una vivienda adecuada y que, a diferencia de los primeros, no tienen recursos suficientes para pagarse un billete de avión o costearse una embarcación legal o ilegal.

Al igual que Pogge, considero que el problema de los refugiados debe ubicarse como parte de una estructura global que reproduce profundas desigualdades económicas: la crisis migratoria es, en suma, el nuevo síntoma de un capitalismo enfermo de desigualdad crónica. Entonces, muchos de los

${ }^{6}$ Thomas Pogge, "Injusticia y deberes frente a los refugiados"[en Johnny Antonio Dávila, ed y trad.: Moral, justicia y derechos humanos, Medellín, Editorial Universidad Pontificia Bolivariana, 2017] p. 122.

${ }^{7}$ Multidimensional Poverty Peer Network, Índice de Pobreza Multidimensional 2019. Recuperado de: https://mppn.org/es/2019ipmglobal/, 2019, (último acceso: 10.05.2021).

8 Thomas Pogge, "Injusticia y deberes frente a los refugiados"[en Johnny Antonio Dávila, ed y trad.: Moral, justicia y derechos humanos, Medellín, Editorial Universidad Pontificia Bolivariana, 2017], p. 123.

Araucaria. Revista Iberoamericana de Filosofia, Política, Humanidades y Relaciones Internacionales, año $23, \mathrm{n}^{\circ} 48$. Tercer cuatrimestre de 2021. Pp. 551-576. ISSN 1575-6823 e-ISSN 2340-2199 https://dx.doi.org/10.12795/araucaria.2021.i48.25 
llamados inmigrantes económicos son, realmente, refugiados de la pobreza y no existirían "si tuviéramos un orden económico global más igualitario, un orden que hiciera más fácil para la mitad más pobre de la humanidad alcanzar vidas que merezcan la pena"

En sus obras más recientes, Thomas Pogge escudriña en las razones que explican por qué la desigualdad hoy es tan grande y llega a una valiosa conclusión: la desigualdad se afianza, según él, por la forma competitiva como organizamos el mundo social y económico. La competencia atraviesa todas las esferas de la vida del individuo y los grupos sociales $y$, aunque la competencia sea un grandioso impulso para el progreso humano, en ella no siempre ganan quienes trabajan más fuerte o hacen mejor las cosas: en el contexto del capitalismo contemporáneo el éxito en la competencia suele ser de aquellos con capacidad para influir, cooptar o abrogarse el contenido y la aplicación de las reglas con que se compite.

A lo anterior Pogge le denomina captura regulatoria, el medio por el cual se logra una mayor influencia sobre las reglas de la competencia. En el ámbito internacional, los más poderosos, las élites de países como los Estados Unidos, afirma Pogge, tienen mayor capacidad para influir en las reglas de la competencia y en su aplicación. En los últimos treinta años, a través del lobby internacional y las negociaciones a puerta cerrada entre corporaciones y gobiernos, los más ricos logran mejores oportunidades y medios para la captura regulatoria, lo que en últimas les hace más poderosos: cerrando así un círculo de opulencia. Desde la óptica del autor alemán, las desigualdades se gestan en la conformación de una nueva arquitectura global que permite que unas pocas personas poderosas influyan sobre las reglas de competencia y su aplicación; de manera que maximizan sus intereses, mientras que obstaculizan el porvenir de una inmensa mayoría global.

No realizaremos una reconstrucción de los argumentos que ofrece Pogge para explicar que la responsabilidad moral frente a la enorme desigualdad que genera la captura regulatoria recae, principalmente, en las instituciones de los Estados más ricos y las personas que las conforman. En este artículo nos ubicamos en el mismo punto de partida de Pogge: el juego de la captura regulatoria y la forma como puede justificarse una moralidad en la arena internacional, pero tomaremos un rumbo distinto. Nuestra mirada no se dirige a las personas e instituciones de las economías más avanzadas, sino hacia los individuos y gobiernos de los países menos desarrollados. Nos interesa sustentar un enfoque que tome a los Estados que padecen de la pobreza extrema en los términos de unidades ontológicas cuyo comportamiento es susceptible de ser analizado éticamente.

\footnotetext{
9 Thomas Pogge, "Injusticia y deberes frente a los refugiados”[en Johnny Antonio Dávila, ed y trad.: Moral, justicia y derechos humanos, Medellín, Editorial Universidad Pontificia Bolivariana, 2017], p. 122.
}

Araucaria. Revista Iberoamericana de Filosofía, Política, Humanidades y Relaciones Internacionales, año $23, \mathrm{n}^{\circ} 48$. Tercer cuatrimestre de 2021. Pp. 551-576. ISSN 1575-6823 e-ISSN 2340-2199 https://dx.doi.org/10.12795/araucaria.2021.i48.25 
En este artículo nos interesa defender que, en las últimas tres décadas no solo se ha ido forjando una nueva arquitectura internacional que reproduce los intereses de los más poderosos, sino una cierta ética de la interdependencia que encierra a los Estados desarrollados y no desarrollados, a las empresas y los organismos internacionales en una especie de finger trap, de manera que: más buscan zafarse uno del otro; para imponerse a través de sanciones, agresiones y hostilidades, más se aprietan sus vínculos, más sujetos están entre sí. Es en ese contexto que se define lo que Pogge denomina captura regulatoria: no es un terreno per se controlado por las élites globales, sino un campo de batalla internacional en los que confluyen diversas formas de imponer los contenidos a las reglas de la competencia y a su aplicación, y en el que los gobiernos de los Estados menos desarrollados tienen una responsabilidad fundamental.

A nivel metodológico, este artículo resulta de una revisión documental filosófica que consistió en actualizar el planteamiento libertario de Jean-Paul Sartre en un diálogo hipotético con Carl Schmitt y con autores contemporáneos como Jürgen Habermas ${ }^{10}$, Cristina Lafont ${ }^{11}$, Thomas Pogge ${ }^{12}$, Slavoj Žižek ${ }^{13}$ y David Harvey ${ }^{14}$. En las páginas siguientes tomaremos la estrategia argumentativa de Sartre, aquella que el pensador francés empleó para explicar la libertad en los individuos, pero adaptada para indagar en los detalles de una posible ética interestatal en el siglo XXI ${ }^{15}$.

La evidencia empírica de esta investigación se centró en demostrar doce casos de aplicación del concepto de mala fe a cincuenta y siete de delitos contra los derechos humanos cometidos por gobiernos de Latinoamérica entre 1980 y 2014, de los cuales resultaron beneficios para compañías extractivas de países desarrollados ${ }^{16}$. Estos casos investigados, por la Corte Interamericana de Derechos Humanos (Corte IDH) ejemplifican el "lado b" de la captación regulatoria que explica Pogge; son la última consecuencia del Lobby; la cara lóbrega y realista que asoma más allá de la influencia sobre las reglas. La elección de estos casos no es fortuita; todos los delitos han sido juzgados en

${ }^{10}$ Jürgen Habermas, "The Concept of Human Dignity and the Realistic Utopia of Human Rights" en Metaphilosophy, 41 (2010) pp. 464-480.

${ }^{11}$ Cristina Lafont, Democracy without shortcuts: A participatory conception of deliberative democracy. Oxford University Press, pp. 191-242

12 Thomas Pogge, "Severe Poverty as a Violation of Negative Duties", en Ethics and International Affairs, 19 (2005), pp. 55-83. doi: https://doi.org/10.1111/j.1747-7093.2005.tb00490.x

${ }^{13}$ Slavoj Žižek, Trouble in paradise: From the end of history to the end of capitalism. Reino Unido, Melville house, 2015, pp: 15-144 y Slavoj Žižek, Pandemia. La COVID-19 estremece al mundo, Barcelona, Anagrama, 2020, pp: 37-43.

${ }^{14}$ David Harvey, "Política anticapitalista em tempos de COVID-19", Revista Sin Permiso, 22, (2020) 1-11.

${ }^{15}$ Se aplica una metodología cualitativa a partir de los aportes metodológicos sobre el realismo en la filosofía de Gerard Delanty \& Piet Strydom, (eds.) Philosophies of Social Science: The Classic and Contemporary Readings, Reino Unido, Open University, 2003, pp: 61-63.

${ }^{16}$ Se analizaron doce sentencias de la Corte IDH, además de bibliografía de contexto (fuentes secundarias y prensa) sobre los hechos en cada caso. 
el sistema regional de protección de derechos humanos entre 1993 y 2021, por lo tanto no solo sirven para describir el problema, sino que nos permiten demostrar que, si se fortalecen, los sistemas de protección regional de los derechos humanos, especialmente el interamericano y el africano, pueden ofrecer una posible solución a la extrema desigualdad como contrapesos institucionales útiles en la tarea de contener el ímpetu desbocado de las élites de los Estados desarrollados.

\section{Libertad, Moralidad y Existencialismo en las Relaciones Internacionales}

Como es sabido, Jean-Paul Sartre no planteó una teoría ética de manera sistemática y acabada, menos aún se planteó emplearla al nivel de las relaciones entre Estados. En la parte final de El Ser y la Nada anuncia una próxima obra en la que desarrollaría su ética, pero esta nunca salió a la luz ${ }^{17}$. Sin embargo, se puede decir que en el centro de su obra filosófica, literaria y dramática se encuentra el hombre y su libertad, así como su elección para relacionarse con otros sujetos, y esto, claramente, corresponde con una reflexión ética. Lo que nos conduce a Sartre es la posibilidad de comprender su propuesta ética existencialista y elevarla al nivel de los Estados para explicar la forma como éstos se relacionan hoy, ante un trasfondo de enunciados sobre la muerte, la libertad y la interdependencia que coinciden con el laboratorio social que Sartre imaginó al plantear su propuesta teórica. Una ética interestatal, basada en Sartre estaría compuesta por tres elementos fundamentales: la concepción del Estado, adaptada de la concepción sartreana del hombre; una consecuente explicación de la libertad de elección del Estado para actuar en el mundo con otros Estados y una descripción del modo como opera la "intersubjetividad" en los Estados, como actores sociales interdependientes.

Cuando Sartre se refiere a la conciencia del individuo no parte de una conciencia reflexiva, como lo hizo Descartes, sino de un cogito pre-reflexivo. De esta manera, evita caer en el problema del solipsismo, pues la conciencia pre-reflexiva es "trascendente", en el sentido de que pone su objeto como trascendiéndola, como aquello a lo que ella apunta. Sartre explica esto de la siguiente manera: "Toda conciencia, como lo ha demostrado Husserl, es conciencia de algo. Esto significa que no hay conciencia que no sea la posición de un objeto trascendente, o, si se prefiere, que la conciencia no tiene ningún contenido" "18. Este mismo nivel de conciencia puede identificarse en el

\footnotetext{
17 Mariano Arias, "Sartre siglo XXI: lectura materialista de L'Idiot de la Famille”, en Eikasia, Revista de Filosofia, 1 (2006) pp. 1-47

18 Jean-Paul Sartre, El ser y la nada: ensayo de ontología fenomenológica, Madrid, Alianza editorial, 1989, p. 21.
}

Araucaria. Revista Iberoamericana de Filosofía, Política, Humanidades y Relaciones Internacionales, año $23, \mathrm{n}^{\circ} 48$. Tercer cuatrimestre de 2021. Pp. 551-576. ISSN 1575-6823 e-ISSN 2340-2199 https://dx.doi.org/10.12795/araucaria.2021.i48.25 
destino que eligen los pueblos para sí mismos y el lugar que aceptan ocupar en las relaciones con otros Estados. Un Estado, en ejercicio de su soberanía, puede ubicarse en el escenario internacional privilegiando su interés, con una vocación bélica clara, asumiendo la guerra como su "destino manifiesto", mientras que otros Estados se eligen a sí mismos como grandes corporaciones empresariales, otros como "Estados paraísos fiscales" y nada más; los hay inclusive, con la conciencia prudente de un "Estado despensa" de materias primas o "narcoestados", entre otras muchas formas. Los pueblos tienen la libertad para elegirse de determinada manera, su conciencia es vacía en estricto, pero en cada circunstancia histórica, en cada llamado a conformar su gobierno, esa conciencia adquiere el contenido que libremente han elegido para sí.

El orden internacional y sus relaciones de poder hacen que unos Estados, los pocos más poderosos, se elijan normalmente motivados por su interés, mientras que la mayoría de los Estados lo hagan impulsados por la prudencia. Por ejemplo, el dato objetivo de la guerra como el "destino manifiesto" de la política exterior de un supuesto Estado, no está en la conducta de esa nación de manera inmanente, como un contenido inmodificable. La guerra es solo una de las conductas posibles de los Estados, responde a un interés, a un proyecto. Esto significa, en primer lugar, que la relación entre la conciencia del Estado frente a la guerra y la guerra misma depende del interés o la intención inmersa en él. En segundo lugar, toda conciencia del Estado, en cuanto intencional, se trasciende en el objeto exterior, en este ejemplo, la guerra es trascendente a la ética del Estado que la elige su destino, no es inmanente a ella. Es decir, el factor que hace especialmente distintas las relaciones entre Estados en el siglo XXI es que la idea de un Estado de naturaleza internacional como destino inevitable ha sido relegada; el objeto exterior de la conciencia del Estado, la guerra, es trascendente y existente, pero a él no se reducen todas las intenciones e intereses de los pueblos ad eternum ${ }^{19}$.

Como se dijo anteriormente, toda conciencia de los Estados es conciencia de algo. De algo distinto de sí misma y, en este sentido, algo trascendente. Cabe aclarar que la ética de los Estados no se debe interpretar en un sentido kantiano, es decir, sublimada a un objeto fenoménico, como pueden serlo los conflictos internacionales, la diplomacia, los acuerdos o los Tratados entre Estados; no son la apariencia de una realidad subyacente de guerra permanente o de paz mundial, no remiten a un ser verdadero y absoluto que contiene la esencia de las relaciones internacionales. Estos objetos o datos de la realidad internacional son absolutamente indicativos de sí mismos. Es decir que no son de una realidad distinta de ellos mismos, la apariencia convulsiva y errática de

\footnotetext{
${ }_{19}$ Guillermo A. Duque Silva, "De enemigos a «no-amigos»: Transformación del concepto de lo político en la posguerra fría" [en Enrique San Miguel Pérez, editor.: Treinta años sin muro: una nueva Europa en la historia de la democracia y de los derechos humanos, Madrid, Dykinson, 2020], pp. $115-120$
} 
las relaciones internacionales, no oculta una esencia pacífica o bélica de la que se derivaría la ética de los $\operatorname{Estados}^{20}$.

Entonces, las relaciones internacionales suponen la división entre dos niveles ontológicos, en el primero se encuentran los datos y hechos materiales que componen la política exterior de los Estados. En este nivel se encuentran los hechos no susceptibles de reducción a teoría moral alguna que los sintetice, son lo real inenmendable, una mezcla inabarcable de hechos pacíficos y bélicos. En el segundo nivel se encuentra la conciencia de los Estados que, como unidades básicas, son llamadas a fundamentar sus conductas y reflexionar sobre el modo como se relacionan con otros Estados entre dos extremos fundamentales: Estados que responden principalmente a su interés y Estados que responden normalmente con prudencia. Es esta posibilidad de elección donde tendría lugar el germen de la ética en las relaciones internacionales que intentamos dilucidar para, de forma posterior, constatar en el espacio interamericano.

Hemos dicho que toda conciencia es siempre conciencia de algo. Esto quiere decir, en el escenario global que nos interesa, que una ética de los Estados necesita siempre de lo real incontenible que aportan las relaciones internacionales para ser conciencia estatal. En este sentido, la conciencia de los Estados debe ser distinta del conflicto internacional como hecho objetivo, o de la diplomacia, los acuerdos, las alianzas, del servilismo o el imperialismo; es decir, debe ser un no-ser de todas esas manifestaciones. Por lo tanto, la ética de los Estados surge mediante una negación o nihilización de los hechos que componen la convulsa realidad interestatal. La naturaleza misma de la ética de un Estado es distanciamiento o separación respecto a la realidad objetiva de la guerra o la paz en las relaciones internacionales. La ética de los Estados, en este sentido, es el resultado de la negación de la realidad internacional objetiva, y su actividad, es un proceso de nihilización.

Cuando un Estado hace uso de su ética al percatarse de la existencia de una guerra, por ejemplo, se distancia de la misma, niega que su ética inevitable indique el "hacer la guerra" per se; y hace que la guerra aparezca como un fenómeno que se resalta de su trasfondo, negando que ésta sea cualquier otra cosa, anulando o nihilizando los demás fenómenos posibles en las relaciones entre Estados. En otras palabras, los Estados alcanzan una ética por una constante separación o distanciamiento de los hechos objetivos que generan y que componen el acontecer internacional. De otra forma, no tendría sentido hablar de libertad en la guerra, de un ius ad bellum y menos aún de un ius in bello; tampoco de las otras maneras de relacionamiento entre Estados; porque la guerra hace parte de la primera dimensión ontológica de los Estados, no es reductible a ninguna teoría moral, simplemente es. Eso no era lo que

${ }^{20}$ Carl Schmitt, "La relación entre los conceptos «Guerra» y «Enemigo»" [en Héctor Orestes coord. y Angelika Scherp trad.: Carl Schmitt, Teólogo de la Política, 2001], p. 147.

Araucaria. Revista Iberoamericana de Filosofia, Política, Humanidades y Relaciones Internacionales, año $23, \mathrm{n}^{\circ} 48$. Tercer cuatrimestre de 2021. Pp. 551-576. ISSN 1575-6823 e-ISSN 2340-2199 https://dx.doi.org/10.12795/araucaria.2021.i48.25 
sucedía en el paradigma westfaliano en el orden mundial moderno, en el que las relaciones internacionales se configuraban como un estado de naturaleza hobbesiano, irreductible a la mínima conciencia. Aquella interpretación hacía inútil cualquier criterio de justicia global ${ }^{21}$. Es decir, no había diferencia entre lo que sucede en las relaciones internacionales como hechos objetivos y la conciencia de los Estados frente a esos mismos hechos. En cambio, hoy, los diferentes Estados pueden justificar o fundamentar sus acciones como algo separado de las mismas relaciones internacionales, su conciencia soberana es indeterminada, se escapa de la determinación de la guerra o la paz en sí y, por tanto, es esencialmente libre.

\section{Soberanías condenadas a ser libres}

Sartre hace referencia a Fiódor Dostoievski cuando escribe: si Dios no existiera, todo estaría permitido. Según Sartre, este es precisamente el punto de partida del existencialismo ateo que él representa, y de su ética ${ }^{22}$. Efectivamente, todo está permitido si Dios no existe. Esto significa que los hombres se encuentran abandonados, arrojados en el mundo, y sin nada ni nadie a qué aferrarse o justificarse; pues bien, si los Estados, como los hombres, son completamente responsables de lo que hacen apelando al sentido último del concepto de soberanía, de razón de Estado o de razón pública es porque en algún sentido también se encuentran "arrojados en el mundo". Los pueblos son autores de su devenir y autores también de los fines que guiarán este devenir y no solo en el momento de elegir a sus gobernantes, sino en cada día en que el demos les permite abrogarse el poder de administrarlo. En este sentido, la ética de los Estados está desprovista de todo cobijo soberano internacional, no reina sobre ella ni el gobierno de la guerra, ni el de la paz absolutas; hay conciencia estatal en la medida en que no hay un Dios que gobierne las relaciones internacionales. Es decir que los Estados aprenden a través del mundo que nada los sostiene, o mejor, que los sostiene la inexistencia de una moral exterior a sus propios fundamentos. Este mundo infundado es lo que fundamenta, paradójicamente, que los Estados sean libres en el ejercicio de sus soberanías, pues no tienen que responder ante ningún gobierno mundial, sino ante sí mismos y aquello con lo que se comprometieran.

Entonces, la libertad es una característica fundamental de los Estados. No existe diferencia entre el ser de los Estados y su libertad, los Estados sólo pueden ser en cuanto son libres, es decir soberanos; luego un Estado sin

\footnotetext{
${ }^{21}$ Timothy Stanton,'Hobbes and Schmitt” en History of European Ideas, 2 -37 (2011), p. 64.

${ }^{22}$ Ismael Nazario Millán, Sartre y Foucault: diálogo en torno a la noción de esencia y estructura, Master's Thesis en filosofía de la Universidad Autónoma del Estado de México, 2017, p. 8.
} 
soberanía deja de ser Estado. De hecho, las acciones de los Estados le ubican como la unidad ontológica libre por naturaleza; más aún, y discrepando de Sartre, que los propios hombres. En este sentido, la esencia de los Estados es pura actividad libre para su despliegue en el escenario internacional. Para los Estados, aunque no tengan naturaleza, sus características son sus actos. Los Estados no son más que el conjunto de sus actos, particularmente aquellos que lo involucran con otros Estados y actores internacionales como las empresas, también los que le involucran con su ciudadanía. Por ello, la libertad de un Estado consiste en que, además del hombre, sea la única unidad ontológica capaz de concebirse tal como se proyecta a través de sus acciones.

Ahí está la importancia de la elección de los actos, y la base de la ética de los Estados que intentamos descifrar. Mientras en el mundo objetivo de las relaciones internacionales, primera dimensión de la ontología estatal, lo real es irreductible a ningún marco normativo, en el fuero interno de los Estados; es decir en sus aparatos administrativos de control y de deliberación, en sus altos tribunales de justicia, sus parlamentos y gobiernos reside la facultad de reflexionar sobre los hechos de los Estados como unidades libres. Esto significa que los motivos de los actos soberanos, la finalidad que cada Estado les atribuye, está predeterminada por la elección de sí mismos. Es decir que, si el gobierno de un Estado ya se ha elegido como cobarde o servil en la arena internacional, motivado más por la prudencia que por la salvaguarda de su interés, siempre encontrará razones y justificaciones para no intervenir en una situación concreta que ponga en peligro a sus propios ciudadanos; ya encontrará razones para no actuar valientemente. Esta idea de libertad implica que las circunstancias, lo dado o real, no determina, ni condiciona, la elección de los Estados; de ahí el desplazamiento con el paradigma de la guerra como estado natural internacional: cualquiera que fuera el carácter del Estado, es siempre el resultado de una elección de sus gobiernos y depende de ellos mismos elegirse como gallardos o pusilánimes, depende de sí mismos ser consecuentes con el mandato popular al que representan.

La libertad de los Estados radica, por tanto, en la capacidad soberana de proyectarse hacia un fin, elegir la propia existencia en dicho proyecto y comprometerse con él en cada acción interior y exterior que realiza. Es imposible para los Estados no experimentar su propia libertad, pues no pueden "dejar de elegir". Si analizamos esta cuestión con detenimiento, vemos que incluso rehuir la elección es también una forma de elegir. En este sentido y trascendiendo el planteamiento de Sartre, exclusivo para el individuo, los Estados también están condenados a ser libres. De lo único que los Estados no son libres es de cesar de ser libres, es decir, la libertad de los Estados, como unidades soberanas, no tiene más límites que ella misma ${ }^{23}$.

${ }^{23}$ Žižek da un ejemplo de una "decisión por omisión” en su crítica a la apertura de la UE: irreflexiva 
La libertad, en este caso, precede a la esencia y la hace posible. Sólo los pueblos que son libres de elegir su propio destino y de actuar conforme a él, van configurando una esencia, pues son sus actos los que, a la postre, le definirán. Tampoco se debe pensar que la elección original o el proyecto de Estado asumido anulan la libertad. La elección fundamental sobre el carácter de un Estado les abre un abanico de posibilidades. Además, la libertad se manifiesta también en que siempre es posible cuestionar o reafirmar el proyecto original que se ha planteado un Estado a través de los cambios electorales en las dirigencias o administraciones de estos y las prioridades que se definan en sus agendas de gobierno. Esto significa que, como sucede con el hombre, en los Estados ni siquiera el proyecto original es definitivo o inmodificable. Inclusive un país como los Estados Unidos, por ejemplo, puede redirigir su política exterior de vocación bélica intervencionista, hacia otro "destino manifiesto"; el único destino inmodificable de los Estados es la libertad de elegirse y el de los pueblos la libertad para dotar de contenido esa decisión; en efecto; el contenido de la elección varía conforme a las coyunturas históricas y siempre puede tener lugar un "nuevo proyecto original".

Esta libertad absoluta de los Estados puede parecer, en algunos puntos, inverosímil, pues se podría argumentar que existe toda una clase de factores externos e internos que limitan la libertad de los Estados y sus soberanías, como los factores estructurales de la división económica internacional, la deuda externa, las diferencias armamentísticas, la concentración de la riqueza, las condiciones geográficas, entre otros. Sin embargo, en la consecución de un destino fundamental para los pueblos, aparecen cosas que pueden ser interpretadas y asumidas como obstáculos insuperables para los Estados, o como oportunidades únicas; depende enteramente, y en última instancia, de la elección de cada pueblo. Esa elección, para que sea legítima deberá apuntar a la meta fundamental de la deliberación política: el convencer los corazones y las mentes de la ciudadanía: "sin fisuras entre pueblo y tecnocracia y $\sin$ atajos populistas" ${ }^{24}$, en eso consiste el ideal democrático puro que nos ha recordado recientemente Cristina Lafont, el cual sería un reverso político apropiado para la ética de la libertad que aquí estamos analizando en la conducta de los Estados.

Es cierta la salvedad que indica que los Estados son incapaces de modificar o controlar completamente los factores externos, en el sentido de alterarlos o alejarse de ellos. A pesar de ello, el significado que tengan estos factores depende enteramente de sí mismos, es decir, los eligen ellos mismos como pueblos, aunque no sepan o se rehúsen a reconocerlo. El

ante las causas de la emigración siria en 2015. Slavoj Žižek, Against the double blackmail: Refugees, terror and other troubles with the neighbours, Reino Unido, Penguin, pp. 16-23

${ }^{24}$ Cristina Lafont, Democracy without shortcuts: A participatory conception of deliberative democracy. Oxford University Press, pp. 134-136

Araucaria. Revista Iberoamericana de Filosofia, Politica, Humanidades y Relaciones Internacionales, año $23, \mathrm{n}^{\circ} 48$. Tercer cuatrimestre de 2021. Pp. 551-576. ISSN 1575-6823 e-ISSN 2340-2199 https://dx.doi.org/10.12795/araucaria.2021.i48.25 
final de una guerra o la destrucción que puede generar, por ejemplo, la dependencia económica o una deuda pública en apariencia insuperable, pueden aparecer como un obstáculo, mientras que la misma cosa puede suponer a otro Estado una oportunidad para plantear un "nuevo proyecto original".

De igual manera, los Estados no pueden alterar el pasado, pues un gobierno no puede cambiar las decisiones que se tomaron tiempo atrás o las cosas que hicieron sus predecesores. Estos hechos del pasado son inalterables. Lo que un pueblo y su gobierno sí pueden hacer, es alterar el significado que le dan a su pasado. Entonces, la ética de los Estados constituye, por un lado, un permanente huir de aquello que los pueblos fueron, hacia lo que serán, es un proyectarse hacia el futuro. Por otro lado, conforma un compromiso de fidelidad con la participación para cerrarle el paso "versiones de Estado" que no se ajusten a lo que la ciudadanía ve de sí misma: al final una sociedad no puede ser mejor que sus miembros ${ }^{25}$, si algo así surge es porque dicha sociedad que ha elegido a sí misma a partir de una "falsa versión de sí".

\section{El "infierno" de la Comunidad Internacional: el peso de la mirada de las Otras soberanías.}

La libertad -tal como se ha planteado en esta particular desviación de la mirada de Sartre hacia las relaciones internacionales-implica que los Estados no sólo carguen con el deber respecto de lo que son individualmente, sino con la responsabilidad frente a lo que generan hacia los demás Estados. Cuando los Estados realizan una elección, por ejemplo, sobre su estrategia de política exterior, se eligen a sí mismos y están eligiendo a todos los demás Estados. En otras palabras, todo lo que ocurre en el plano de las relaciones internacionales debe atribuirse a la libertad y la responsabilidad de la elección originaria y soberana de cada Estado. Por supuesto que hay otros actores y circunstancias fuera del control de las soberanías, como la influencia de empresas y conglomerados económicos, la dependencia a fondos de crédito internacional como el FMI y el BM, también la acción de organismos multilaterales como la OMC y la OMS que un Estado debe tener en cuenta antes de decidir su lugar en la escena internacional; hay mucho que deliberar antes de concretar lo que Habermas ha llamado "política interior mundial" de los Estados ${ }^{26}$. Esta profunda responsabilidad, este compromiso que los administradores de los Estados adquieren con su ciudadanía, y al mismo tiempo con los demás Estados

\footnotetext{
${ }^{25}$ Cristina Lafont, Democracy without shortcuts: A participatory conception of deliberative democracy. Oxford University Press, pp. 144-145

26 Jürgen Habermas,"The Concept of Human Dignity and the Realistic Utopia of Human Rights" en Metaphilosophy, 41 (2010), pp. 464-80.
}

Araucaria. Revista Iberoamericana de Filosofia, Politica, Humanidades y Relaciones Internacionales, año $23, \mathrm{n}^{\circ} 48$. Tercer cuatrimestre de 2021. Pp. 551-576. ISSN 1575-6823 e-ISSN 2340-2199 https://dx.doi.org/10.12795/araucaria.2021.i48.25 
y agentes internacionales, cada vez que actúan, produce en los dirigentes, en términos sartrianos; "angustia"27.

El Estado que se compromete sabe que al elegirse a sí mismo entre interesado o prudente, se convierte también en un legislador de toda la civilización, pues elige también a toda la humanidad, por ello no puede escapar de un sentimiento de total y profunda responsabilidad ${ }^{28}$. La angustia, como la definió Sartre, es un tipo de conciencia reflexiva de la libertad, y esta se ve, de hecho, más claramente en los Estados que en los hombres; a diferencia de lo que planteó Sartre las consecuencias negativas y el daño a los otros y a sí mismos es más palpable en cada decisión de Estado que en decisiones individuales, poco visibles, ya que con una decisión en relaciones internacionales se puede, realmente, afectar a la humanidad en su conjunto, pues se tiene capacidad real para ello. Así, la libertad se revela a los gobiernos de los Estados por la angustia que genera el hecho de elegir sus actos de política exterior, bajo el riesgo de dañar a los demás Estados o a su propia ciudadanía y en ocasiones, en el hecho mismo de tener que elegir a cuál de estas dos partes se le hace conscientemente un daño, para preservar a la otra.

No obstante, en general, los Estados toman conciencia de su libertad en la angustia de sus gobiernos para elegirse a sí mismos como prudentes o interesados. Sartre, explica que la angustia es como el vértigo que experimenta quien se halla al borde de un precipicio, no por temor a caer, sino debido a la tentación de querer arrojarse a él. En efecto, en una situación tal, se puede sentir miedo al contemplar la posibilidad de caerse al precipicio, tal vez porque se podría pisar sobre una piedra suelta o algo similar. Del mismo modo, ante el inicio de un conflicto armado, la firma de una nueva alianza comercial o el inicio de una nueva temporada electoral en países clave como los Estados Unidos o Rusia, cada gobernante de cada Estado se contempla a sí mismo en medio de hechos objetivos y trascendentes; se torna inevitablemente en un objeto más que no tiene control sobre su destino, asume el riesgo de ser presa de otros proyectos. Reconocerse como trascendente, o como un "objeto en medio de los objetos" 29 ; un dato más de la guerra, por ejemplo, genera la necesidad de reflexionar acerca de las maneras posibles de evitar la amenaza de caer al precipicio. Es decir, si los Estados reconocen que su integridad está en peligro, intentarán ser muy cuidadosos y actuar con prudencia, para tener el mayor control posible de la situación, y de esa manera alejar de sí todo

${ }^{27}$ Luis Alfonso Torres Ramis, El “otro" como sujeto y no como objeto: aclaraciones sobre el concepto del otro en El ser y la nada de Jean-Paul Sartre, Master's Thesis Universidad Nacional Mayor de San Marcos, 2018, p. 69.

${ }_{28}$ Guillermo A. Duque Silva, Realistic Cosmopolitanism: The Control of Conventionality as an instrument for international distributive justice, Thesis Doctoral, Universitat de Barcelona, 2021, p. 14

${ }^{29}$ Vicente Verdú, Yo y tú, objetos de lujo: el personismo: la primera revolución cultural del siglo XXI, Barcelona, Debate Editorial, 2006, p. 49

Araucaria. Revista Iberoamericana de Filosofia, Politica, Humanidades y Relaciones Internacionales, año $23, \mathrm{n}^{\circ} 48$. Tercer cuatrimestre de 2021. Pp. 551-576. ISSN 1575-6823 e-ISSN 2340-2199 https://dx.doi.org/10.12795/araucaria.2021.i48.25 
lo que pueda poner en peligro su integridad. Sin embargo, estos esfuerzos por resguardarse pueden ser inútiles, pues la integridad de los Estados no sólo se ve amenazada por los objetos del mundo o por los demás Estados, sino que ellos mismos se convierten en posibles causantes de su perjuicio, los Estados como responsables de sus propias acciones pueden ocasionarse a sí mismos la caída al precipicio y esto genera en su ser, no miedo, sino angustia.

Esta situación aplicada, en estricto, a las relaciones internacionales se hace evidente en el siglo XXI, debido a las altas cuotas de dependencia interestatal que vivimos. En varias ocasiones vemos que a la hostilidad entre Alemania y la UE con Rusia, por ejemplo, se le ha sumado la angustia de perder el suministro de gas de Gazprom en buena parte de Europa central y del Este, hemos visto retrotraer las sanciones, por justificadas que parezcan las acciones hostiles contra Rusia $^{30}$. De la misma forma que cualquier intervención militar en Venezuela se pierde tras los bastidores al recordarse el dato objetivo que indica que aquella es la misma nación que puede poner en vilo el $70 \%$ del suministro de petróleo crudo en el hemisferio occidental, la segunda en el mundo ${ }^{31}$. Recientemente hemos notado cómo un eventual bloqueo comercial a China como consecuencia de una crisis diplomática post-covid; tendría repercusiones positivas $^{32}$ y negativas ${ }^{33}$ en todos los países del mundo, del mismo modo que evitar pagar o desconocer una deuda a entidades financieras como el FMI y el BM puede generar, a cualquier país de renta media que se lo plantee, una crisis comparable con la dolorosa "caída a un precipicio" que describió Sartre. El conjunto de las realizaciones posibles de los Estados incluye, no sólo tomar las medidas de seguridad y prudencia necesarias para evitar hacerse daño, como sería "fijarse muy bien dónde pisan" los Estados cuando formulan su política estratégica internacional, sino que incluye, también, la posibilidad de asumir conductas contrarias a su propio bienestar como un curso posible. Es decir, no sólo es una de las conductas alternas de los gobiernos el dejar de prestar atención al camino que transitan; también lo es el lanzarse, ellos mismos, al precipicio. Esa última decisión da lugar a lo que conocemos en la ética sartriana como mala fe. Veremos esa anomalía ética de la mala fe ha dado lugar a múltiples formas de aplicación en los países de América Latina.

${ }^{30}$ Anna Alon \& Peggy Dwyer, "Globalization and multinational auditing: The case of Gazprom and PwC in Russia" en Behavioral Research in Accounting, 24-1 (2012), pp. 135-160.

${ }^{31}$ Judith Ewell, Venezuela and the United States: from Monroe's hemisphere to petroleum 's empire. Estados Unidos, University of Georgia Press, 1996, p. 199-201

${ }^{32}$ Daniel Drezner, "The Song Remains the Same: International Relations After COVID-19" en International Organization, 74 (2020), pp. 18-35

${ }^{33}$ David Harvey, "Política anticapitalista em tempos de COVID-19" en Revista Sin Permiso, 22 (2020), pp. 1-11.

Araucaria. Revista Iberoamericana de Filosofí, Política, Humanidades y Relaciones Internacionales, año $23, \mathrm{n}^{\circ} 48$. Tercer cuatrimestre de 2021. Pp. 551-576. ISSN 1575-6823 e-ISSN 2340-2199 https://dx.doi.org/10.12795/araucaria.2021.i48.25 


\section{La mala fe: Estados que se mienten a sí mismos y generan pobreza}

La angustia da lugar a que, con frecuencia, los gobiernos de los Estados asuman una actitud de "negación de sí": esto es lo que se denomina, en lenguaje sartreano mala fe. Esta es una de las diversas formas en que un Estado toma actitudes negativas respecto de sí, contra sí, es decir en detrimento de su propio pueblo. Comúnmente, se asimila la mala fe a la mentira, pero no son lo mismo. La mala fe es un mentirse a sí mismo, lo cual se debe distinguir de la mentira común, pues en la mala fe no existe la dualidad entre el engañador y el engañado, sólo existe la conciencia de afectarse a sí mismo. En la mala fe, los gobiernos como voceros de sus Estados toman decisiones en las que se mienten a sí mismos y creen en la mentira que se dicen, ellos mismos enmascaran una verdad desagradable y presentan como verdad; un error agradable. Es decir que lo característico de la mala fe es que implica la unidad de la conciencia. Aquel al que se miente y aquel que miente: son un mismo sujeto.

Si hicieran falta ejemplos sobre la mala fe, solo bastaría con recordar la forma como el gobierno chileno modificó en 2004 sus leyes sobre protección de los territorios indígenas del pueblo mapuche, para entregar en concesión las fuentes hídricas que permitieron a la empresa española Endesa instalar el proyecto hidroeléctrico "Ralco" 34 ; o bastaría, quizás, con recordar las medidas internas y los argumentos que dio, en 2009, el gobierno de Brasil para desviar un río y ceder parte de la Bahía Sepetiba a favor de la compañía alemana Thyssen Krupp, a la que alquiló terrenos para construir una siderúrgica, con el posterior daño ambiental y social que esto conllevó, por ejemplo con la contaminación con plomo y arsénico de la bahía ${ }^{35}$. Otro ejemplo de mala fe es la modificación de las leyes colombianas que permitieron prorrogar la concesión de una de las más importantes minas de níquel del mundo, "Cerro Matoso", la cual vencía en 2012. Ese mismo año el gobierno colombiano modificó su propia legislación -que prohibía prorrogar o extender concesiones por más de treinta años a una empresa privada extranjera- exclusivamente para renovar la concesión hasta 2044 a la compañía australiana BHP Billiton, socio mayoritario, la cual debía reponer los terrenos con la capacidad instalada al Estado colombiano. El 0,13\% del valor activo que cobra Colombia a la compañía de forma mensual es tan ínfimo, que ésta puede pagar las tres décadas de derechos de explotación de la mina, únicamente con las utilidades netas de los primeros seis años ${ }^{36}$.

34 Catalina Daniela Riquelme Tapia \& Mario Samaniego Sastre, "Pueblos indígenas. Reconocimiento y tensiones político-normativas al interior del espacio público en Chile, 1990-2010" en Estudios políticos, 59 (2020), pp. 46-73.

${ }^{35}$ Cesar Bernardo Ferreira \& Cleonice Puggian, "A desterritorialização causada pela violência bioétnica e os pescadores artesanais da Baía de Guanabara” en Vivência Revista de Antropologia, 1-55 (2020), pp. 219-239.

${ }^{36}$ Manuel Sarmiento, "Cerro Matoso: una historia de fraudes contra el país" en Manuel Sarmiento concejal de Bogotá 2020-2023. Ultimo día de modificación 26 de agosto de 2015. https:// manuelsarmiento.com/cerro-matoso-una-historia-de-fraudes-contra-el-pais/ 
Con la misión de demostrar la existencia de un anti-principio, acto inmoral o delito de mala fe, la investigación ha ido más allá de la adaptación teórica sartreana a las relaciones internacionales, para identificar los casos concretos en que se puede probar que ésta ha tenido lugar como una conducta de los gobiernos contra sus pueblos. En este caso la estrategia ha consistido en estudiar a profundidad las sentencias que, en el ámbito latinoamericano, ha sancionado la Corte IDH contra gobiernos que se han "mentido" a sí mismos o a su propio pueblo a través de leyes, acciones y omisiones que vulneran los derechos humanos a favor de empresas.

El resultado de esa revisión es la clasificación de 12 eventos en los cuáles tuvo presencia un actuar de mala fe en los Estados de Latinoamérica ante la mirada demandante de empresas multinacionales. La siguiente tabla, relaciona los casos estudiados de países en los que ha tenido lugar una conducta grave de mala fe; la empresa extranjera que ha participado alterando el horizonte de libertad del Estado y el gobierno que ha decidido eludir su responsabilidad de actuar en correspondencia con el mandato del demos al que representa.

Los casos analizados son emblemáticos del período 1980-2014. Todos son hechos probados a través de investigaciones de la Corte IDH contra siete Estados. El número total de víctimas calculado en las sentencias supera las 20.000 personas. En la mayoría de los casos, las acciones violentas fueron acompañadas de leyes que buscaban legitimarlas. Los beneficios económicos, en todos los casos, incidieron en la cesión de terrenos para conveniencia de las empresas multinacionales. Lamentablemente, como se muestra en el cuadro, los ejemplos de Estados que incurren en este tipo de conducta de mala fe son muchos y llegan a implicar, incluso, masacres a poblaciones enteras a través de operaciones de "tierra arrasada".

La lógica identificada resalta tres elementos básicos, suficientes y necesarios para que un delito de mala fe se configure con tres partes básicas:

1) La participación de empresas multinacionales con intereses sobre recursos naturales,

2) La complicidad en modo, tiempo y lugar de los gobiernos, en este caso latinoamericanos, que infringen da daños a su ciudadanía a través de:

2.1) Acciones legislativas contrarias a la Convención de Derechos Humanos

2.2) Acciones represivas (Masacres, desplazamientos forzados, detención arbitraria, entre otras)

2.3) La omisión o dilación jurídica, generalmente, para garantizar la impunidad ante acciones represivas o legislativas inconvencionales.

3) El uso de argumentos de mala fe en los gobiernos para negarse a defender el interés que representan: los más recurrentes, según los alegatos de los Estados, son: 
3.1) El interés superior en el progreso.

3.2) La garantía del derecho a la propiedad privada.

3.3) La promoción de la inversión extranjera.

No se puede esperar que surja una especie de jurisdicción que imponga decisiones a los cinco países más ricos, a la manera de medidas que vayan en contra de sus intereses y que sin embargo cuenten con su consentimiento. Si es posible, por el contrario -y ya lo dicta la realidad- el perfeccionamiento de jurisdicciones supraestatales en las regiones más desiguales y pobres del mundo, en las que los Tribunales deciden sancionar a los Estados miembros que venden el porvenir de sus ciudadanos a través de actos corruptos y violaciones a los derechos humanos. Especialmente, si se han comprometido, por ejemplo, con una Convención internacional de Derechos Humanos y sin embargo violan los derechos humanos de sus conciudadanos al actuar de mala $f e$ con la promulgación de leyes que generan su propia exclusión en el usufructo de sus materias primas y otras fuentes de riqueza.

Las vías de realización de la mala fe también varían, en los casos estudiados prevalecen las masacres, frente a la desaparición forzada y la represión a través de leyes que criminalizan la protesta social. Lo que no varía es la violación de derechos humanos como medio de mala fe, luego, se puede indicar que más allá del lobby que generan las grandes corporaciones, la empresa de la acumulación de riqueza requiere de cierto "trabajo sucio" en los países pobres económicamente, aunque ricos en recursos naturales.

Mientras que el lobby no puede judicializarse como una conducta punible, sus últimas consecuencias en los países en desarrollo sí pueden condenarse pues, generalmente, suponen graves violaciones a los derechos humanos. Luego, la cadena de injusticia social global que produce las desigualdades se puede romper en su último eslabón. En otras palabras, aunque las élites de los Estados desarrollados sean los autores intelectuales de la injusticia global, como bien indica Pogge, las hidroeléctricas, las plantaciones pseudo esclavistas y las minas de níquel, oro o bauxita no se crean únicamente con lobby e influencia; para ello se requiere, como hemos visto, de autores materiales que, en el marco de los sistemas de protección regional de los derechos humanos, sean jurídicamente responsables por sus actos. 


\section{Tabla1}

\section{Casos de estudio}

\begin{tabular}{|l|}
\hline \multicolumn{1}{|c|}{ Casos de Estudio } \\
\hline Hechos de mala fe probados por la Corte IDH \\
\hline 1. (1980-1982) Gobierno de Guatemala: Cinco masacres de \\
425 personas en Rio Negro, Aldea Xococ, Cerro Pacoxom, \\
"Los encuentros" y "Aguafría", desaparición forzada de (al \\
menos) 15 personas, 2 ejecuciones extrajudiciales, \\
desplazamiento forzado de 363 sobrevivientes y violación \\
sexual a 10 menores de edad.
\end{tabular}

2. (1982-1987) Gobierno de Guatemala: Masacre de 268 persona en Aldea Plan Sánchez, ataques con granadas por parte de Ejército, abuso sexual y homicidio, desaparición de un número indeterminado de personas en 22 fosas comunes. Hostigamientos a 317 sobrevimientes.

3. (1986-2006) Gobierno de Surinam: firma de una histórica concesión minera por 75 años para las compañías BHP Billiton y Suralco. Parcelación del territorio indígena y venta de títulos a terceros en el marco del proyecto "Tuinstad Albina" y prohibición de realizar actividades económicas a los Pueblos Kaliña y Lokono al declarar la mina "reserva natural"

4. (1986-1998) Gobierno de Paraguay: Explotación sexual, sometimiento a condición de servidumbre, desplazamiento forzado, prohibición de acceso a servicios de salud, agua y alimentación suficiente a 319 indígenas. Concesión de tierras indígenas a empresa privada y Declaración de inexpropibilidad

5. (1987-1999) Gobierno de Surinam: Detención arbitraria y tortura de 20 personas, masacre, condena a muerte $\sin$ razón y obligación a cavar su propia fosa a 7 personas Bushnegroes

\section{Proyecto empresarial \\ Hidroeléctrica del Chixoy}

Instalada sobre los "terrenos arrasados"

Empresas: Lahmeyer (Alemania), Motor

Colombus (Suiza) International

Engineering Col. (Estados Unidos)

Nellolter (Estados Unidos) QUASIM

(Italia) Lamarre Valois Int. Limitee

(Canadá) con créditos del del BID y el $\mathrm{BM}$.

Mina de bauxita "Wane Kreek"

Extracción total de la bauxita en territorio ancestral los Pueblos Kaliña y Lokono

Empresas: BHP Billiton (Australia) y

Suralco-Alcoa (Estados Unidos)

Estancias ganaderas Loma Verdey Maroma

En 18.189 hectáreas de terrenos usurpados a la Comunidad Indígena Yakye Axa

Empresas: Florida Agricultural Corporation (Estados Unidos) Livestock Capital Group Inc. (Estados Unidos) Agricultural Development Inc. (Estados Unidos)

\section{Embalse Brokopondo para Suralco y} BHP Billiton

En la orilla norte del rio Surinam territorio ancenstral de las víctimas miembros de los Pueblos Maroons / Bushnegroes

Empresa: Suralco-Alcoa (Estados Unidos)

6. (1991-2008) Gobierno de Paraguay: Militarización e imposibilidad de la Comunidad Indígena Xákmok Kásek acceder a su territorio a través del Decreto No. 11.804 emitido el 31 de enero de 2008 con el cual los terrenos indígenas se declaran área silvestre protegida de administración privada. Declaración de inexpropibilidad la Estancia Ganadera Salazar.

\section{Estancia ganadera Salazar}

Comprendiendo 10.700 hectáreas del territorio Indígena Xákmok Kásek desplazado del lugar.

Empresa: Eaton y Cia (Estados Unidos) 
7. (1991-1998) Gobierno de Paraguay: Sometimiento a
condición de servidumbre, desplazamiento forzado,
prohibición de acceso a servicios de salud, agua y
alimentación suficiente a 407 indígenas. Dilación sub judice.
Declaración de inexpropibilidad de las fincas No. 16786 y
16784 del empresario alemán Heribert Roedel

8. (1995-1996) Gobierno de Nicaragua: Violación al derecho de consulta previa a comunidad indígena, presión para vender y renunciar a la demanda y Concesión de tierras indígenas a empresa privadas.

9. (1996-2004) Gobierno de Surinam: Desplazamiento forzado de más de 300 personas para construcción de dique Afobaka. Concesiones madereras y mineras a empresas privadas en territorio Matjau del Pueblo Saramaka.
10. (1999-2003) Gobierno de Ecuador: Negativa a realizar la consulta previa libre e informada a comunidad Kichwa para iniciar operaciones petroleras. Sobornos y presiones a líderes Kichwa de Sarayaku por parte de apoderado CGC. Firma de Convenio de Cooperación de Seguridad Militar que imposibilitó de la Comunidad acceder a su propio territorio. Detención ilegal y arbitraria a 5 indígenas Kichwa y agresión a 120 indígenas por participar en marcha contra la CGC y Chevron Burlington

11. (2001-2002) Gobierno de Chile: Cinco detenciones arbitrarias a defensores de derechos humanos. Detención bajo acusación de terrorismo a tres autoridades indígenas. Violación del derecho de la defensa a interrogar testigos. Reforma a la Ley anti-terrorista 18314 eliminando la presunción de inocencia para "legalizar" las capturas.

12. (2007-2014) Gobierno de Honduras: Homicidio de líder indígena denunciante de usurpación de terrenos. Usurpación de tierra indígena de Comunidad Garífuna Violación. Creación de reserva natural Parque Nacional "Sierra Río Tinto" acuerdo 007-2011 para evadir del derecho a la consulta previa a Comunidades Punta Piedra y Cosuna para exploración minera de BG Group plc

\section{Estancia Kansol y Roswell y} Exploración petrolera

Sobre 14.404 hectáreas de territorio originario Sawhoyamaxa

Empresa: Kansol y Roswell Company S.A

(Alemania)

\section{Concesión de madera rolliza}

$$
\text { SOLCARSA }
$$

En los bosques ancestrales del pueblo indígena Comunidad Mayagna (Sumo) poblado Awas Tingni sin consulta previa.

Empresa: Sol del Caribe S.A de Kumk

Yung Co. (Corea del Sur)

\section{Central maderera china NV Lumprexy}

\section{Rosebel mine (Oro)}

Explotación maderera y minera en el sur de Paramaribo hasta la reserva de Brokopondo

Empresas: Jin Lin Wood Industries/ Ji Sheng/NV Lumprex y Tacoba/ Fine Style (China) y Golden Star Resources / Imgold (Canadá)

\section{Exploración petrolera en Amazonía} ecuatoriana

Prospección sísmica con 467 pozos cargados de pentolita en de un $29 \%$ del territorio indígena de Sarayaku.

Empresas: Compañía General de Combustible, CGC (Argentina), Petrolera Argentina San Jorge S.A (Argentina) y Chevron Burlington (Estados Unidos)

Central Hidroeléctrica Ralco del Alto Bio-Bio

Instalada sobre terrenos ancestrales Mapuche

Empresa: Endesa (España)

Exploración minera "Punta Piedra II"/ Hidroeléctrica "Los Chorros"

Ambos proyectos sobre terrenos de la Comunidad Garífuna de Punta Piedra y en la zona marítima de la Mosquitia Empresas: BG Group (Reino Unido)/ Azipetrol (Azerbayán) / CarbiX (Reino Unido) / Korea Electric Power Corporation. (Corea del Sur)

Fuentes: Corte IDH 1993; 2004; 2005a; 2006; 2007; 2010b; 2012a; 2012b; 2014; 2015a; 2015 b. 
Estos casos son importantes porque nos permiten dilucidar el horizonte ético de actuación de los Estados y su propia distorsión, tomando a Latinoamérica como un caso límite. Puede afirmarse, sin temor a equívocos, la existencia de rasgos de mala fe en los gobiernos de las naciones latinoamericanas. La mala $f e$, como ese "engañarse a sí mismo", surge como una desviación en la conducta de un Estado respecto de su ética. Muchos de los Estados en América Latina, asumen, por ejemplo, el costo de permitir masacrar o desplazar a poblaciones campesinas o indígenas como el único camino idóneo hacia el progreso, aunque pueden probar que, por esa vía perpetúan su situación de desventaja competitiva con otros Estados. Esos mismos gobiernos enmascaran, entonces, la desagradable verdad del fracaso a que conduce la "receta" neoliberal frente a su propia ciudadanía y la promueven con golpes de represión e impunidad.

Las víctimas frente a las actuaciones de mala fe analizadas en Latinoamérica también varían. En los casos analizados predominan las comunidades indígenas como un foco del daño que provoca la mala fe; también son las comunidades más atendidas en las reparaciones ordenadas por la Corte IDH. La investigación de la mala fe como sustento moral de los delitos de Estado ha dado lugar, en el caso de Latinoamérica, a formas concretas de reparación transformativas para los pueblos indígenas. En cierto sentido, las reparaciones ordenadas por la Corte IDH han provocado que los Estados se retracten de sus actuaciones de mala fe, instándolos a reparar siendo conscientes de su propia libertad; ordenándoles transformaciones profundas en la calidad de vida de los pueblos indígenas. En estos casos en particular, la Corte IDH ha ordenado, por ejemplo, la construcción de infraestructura hospitalaria, educativa y la creación de fondos de desarrollo social y comunitario como una forma de recomponer el proyecto de vida de comunidades y pueblos.

En resumen, podemos decir que en la mala fe los gobiernos se niegan a superar su propia facticidad y crean artificios que le generan la ilusión de evadir la responsabilidad con su propia libertad. Sin embargo, aunque la angustia que produce la condición de libertad de los Estados y su responsabilidad se enmascare, esta aparece. Al no existir la dualidad del engañador y engañado, la empresa de la mala fe está destinada al fracaso, pues es susceptible de ser revelada, denunciada y, como hemos visto, ser tratada como un posible delito de Estado.

\section{Conclusión}

Como hemos explicado, la elección que toma un Estado sobre sí mismo surge de un choque o lucha de libertades con los demás Estados y poderes internacionales como las empresas. La globalización construye un escenario de 
conflicto de soberanías, algunas de estas se afirman en defensa de su proyecto original y otras soberanías ceden terreno en las decisiones que toman por las exigencias del Otro. Esas opciones delimitan las variables de la prudencia y el interés, como impulsos vitales en la conducta de los Estados.

Los elementos característicos de esta ética de las relaciones internacionales serían tres. Primero, una concepción del Estado como unidad ontológica esencialmente libre; segundo, una libertad de elección de cada Estado para actuar en el mundo con otros Estados y actores transnacionales, como las empresas. En tal sentido, cada pueblo, incluidos los países latinoamericanos en los que hemos enfatizado, pero no solo éstos, son responsables de su propio destino y de su libertad para actuar en el mundo; sin embargo, y, en tercer lugar, esa libertad está restringida por el escrutinio permanente de los otros Estados y sus empresas en cuanto actores sociales interdependientes.

Identificamos la mala fe como una anomalía en la ética de los Estados. Esta conducta es la acción consciente de los gobiernos de rehuir la responsabilidad de actuar en correspondencia con el interés soberano de proteger a su propio pueblo. En la mala fe se encuentra el fundamento de delitos de Estados que se convierten, ellos mismos, en posibles causantes de su perjuicio. La mala fe se ha traducido, en el escenario latinoamericano, en violaciones a los derechos humanos de colectivos y pueblos, justificadas en la defensa del progreso y materializadas en acciones tan graves como las masacres y los desplazamientos forzados.

Se puede concluir que en el siglo XXI tiene lugar una ética de la libertad en las relaciones internacionales. Esto trae una implicación importante en la filosofía del derecho, que debería ser analizada en futuras investigaciones: abre la pregunta acerca de si es posible tipificar un delito de mala fe en el derecho internacional. Considero que, basándonos en la ética que hemos descrito, podría clasificarse y fundamentarse el delito de mala fe como una nueva conducta punible de los Estados cuando con ella los gobiernos dañen, por ejemplo, los derechos humanos de los pueblos bajo la justificación del progreso o el desarrollo económico.

Este artículo ofrece una explicación alterna a la pregunta por las responsabilidades de los Estados que generan pobreza en el globo y que están generando migraciones masivas a los países desarrollados. La característica más novedosa de la investigación consiste en poner en evidencia la mala fe de los gobiernos de los Estados menos desarrollados en la producción de la pobreza. A diferencia de otras perspectivas que también propenden por un cosmopolitismo con justicia social, como la de Thomas Pogge ${ }^{37}$, este enfoque ha logrado demostrar que las acciones de los gobiernos de países en desarrollo, en contra

37 Thomas Pogge, Hacer justicia a la humanidad, México, Fondo de Cultura Económica, 2012, p. 526

Araucaria. Revista Iberoamericana de Filosofia, Política, Humanidades y Relaciones Internacionales, año $23, \mathrm{n}^{\circ} 48$. Tercer cuatrimestre de 2021. Pp. 551-576. ISSN 1575-6823 e-ISSN 2340-2199 https://dx.doi.org/10.12795/araucaria.2021.i48.25 
del porvenir de su propio pueblo, se hallan en el centro de la reproducción de la injusticia económica internacional. Puede ser cierto que la corrección de las asimetrías en estos países no solucione la situación de desastre general que ha provocado el capitalismo, sin embargo, un examen de la mala fe en los gobiernos de Estados con economías débiles, como aquel atajo que les permite eludir la responsabilidad que acompaña al ejercicio de la libertad soberana, constituye un punto de partida bastante promisorio en la carrera por construir un mundo menos injusto y por finalizar, en origen, las caravanas mortales de refugiados de la pobreza.

\section{Bibliografía:}

Alon, Anna, \& Dwyer, Peggy, "Globalization and multinational auditing: The case of Gazprom and PwC in Russia", Behavioral Research in Accounting, 24 -1 (2012), pp: 135-160.

Arias, Mariano. "Sartre siglo XXI: lectura materialista de L'Idiot de la Famille”. Eikasia, Revista de Filosofía, 1 (2006), pp. 1-47.

CIDH. Caso Mayagna (Sumo) Awas Tingni vs. Nicaragua, Serie C, núm. 79. Sentencia de 31 de agosto de 2001. Washington D.C: OEA. 2001.

Corte IDH. Caso Aloeboetoe y otros vs. Surinam (Reparaciones y Costas). Sentencia de 10 de septiembre de 1993. Washington D.C: OEA. 1993.

Corte IDH. Caso Masacre Plan de Sánchez vs. Guatemala (Reparaciones). Sentencia de 19 de noviembre de 2004. Washington D.C: OEA. 2004.

Corte IDH. Caso Comunidad indígena Yakye Axa Vs. Paraguay. Sentencia de 17 de junio de 2005 (Fondo, Reparaciones y Costas). Washington D.C: OEA. 2005a.

Corte IDH. Caso de la Comunidad Moiwana Vs. Suriname. Sentencia de 15 de junio de 2005 (Excepciones Preliminares, Fondo, reparaciones y Costas). Washington D.C: OEA. 2005b.

Corte IDH. Caso Comunidad Indígena Sawhoyamaxa Vs. Paraguay. Sentencia de 29 de marzo de 2006 (Fondo, Reparaciones y Costas). Washington D.C: OEA. 2006.

Corte IDH. Caso Saramaka vs. Surinam (Excepciones Preliminares, Fondo, Reparaciones y Costas). Sentencia de 28 de noviembre de 2007. Washington D.C: OEA. 2007.

Corte IDH. Caso Chitay Nech y otros vs. Guatemala. Sentencia de 25 de mayo de 2010 (excepciones preliminares, fondo, reparaciones y costas). Washington D.C: OEA. 2010a. 
Corte IDH. Caso Comunidad Indígena Xákmok Kásek Vs. Paraguay. Sentencia de 24 de agosto de 2010 (Fondo, Reparaciones Y Costas). Washington D.C: OEA. 2010b

Corte IDH. Caso Sarayaku vs. Ecuador (Fondo y Reparaciones). Sentencia de 27 de junio de 2012. Washington D.C: OEA. 2012a.

Corte IDH. Caso Masacres de Río Negro Vs. Guatemala Sentencia de 4 de septiembre de 2012 (Excepción Preliminar, Fondo, Reparaciones y Costas). Washington D.C: OEA. 2012b.

Corte IDH. El Mozote y lugares aledaños vs. El Salvador Sentencia de 25 de octubre de 2012 (Excepción Preliminar, Fondo, Reparaciones y Costas). Washington D.C: OEA. 2012c.

Corte IDH. Caso Norín Catrimán y otros (Dirigentes, miembros y activista del Pueblo Indígena Mapuche) vs. Chile. Sentencia de 29 de mayo de 2014 (Fondo, Reparaciones y Costas). Washington D.C: OEA. 2014.

Corte IDH. Caso Comunidad Garifuna de Punta Piedra y sus Miembros Vs. Honduras Sentencia de 8 de octubre de 2015 (Excepciones Preliminares, Fondo, Reparaciones y Costas). Washington D.C: OEA. 2015.

Corte IDH. Caso Pueblos Kaliña Y Lokono Vs. Surinam Sentencia de 25 de noviembre de 2015 (Fondo, Reparaciones Y Costas. Washington D.C: OEA. 2015 b.

Delanty, Gerard \& Strydom, Piet (eds.), Philosophies of Social Science: The Classic and Contemporary Readings, Open University, 2003.

Drezner, Daniel, "The Song Remains the Same: International Relations After COVID-19” en International Organization, 74 (2020), pp. 18-35

Duque, Guillermo Andrés, "De enemigos a «no-amigos»: Transformación del concepto de lo político en la posguerra fría” [en Enrique San Miguel Pérez, editor.: Treinta años sin muro: una nueva Europa en la historia de la democracia y de los derechos humanos, Madrid, Dykinson, 2020], pp. 93-119.

Duque, Guillermo Andrés, Realistic Cosmopolitanism: The Control of Conventionality as an instrument for international distributive justice, Thesis Doctoral, Universitat de Barcelona, 2021.

Ewell, Judith, Venezuela and the United States: from Monroe's hemisphere to petroleum's empire. Estados Unidos, University of Georgia Press, 1996

Ferreira, Cesar Bernardo \& Puggian, Cleonice, "A desterritorialização causada pela violência bioétnica e os pescadores artesanais da Baía de Guanabara" en Vivência Revista de Antropologia, 1-55 (2020), pp. 219-239.

Habermas, Jürgen, "The Concept of Human Dignity and the Realistic Utopia of Human Rights” en Metaphilosophy, 41 (2010), pp. 464-80.

Harvey, David, "Política anticapitalista em tempos de COVID-19", Revista Sin Permiso, 22, (2020) 1-11. 
Nazario Millán, Ismael, Sartre y Foucault: diálogo en torno a la noción de esencia y estructura, Master's Thesis en filosofía de la Universidad Autónoma del Estado de México, 2017.

Pogge, Thomas, "Severe Poverty as a Violation of Negative Duties", en Ethics and International Affairs, 19 (2005), pp. 55-83.

Pogge, Thomas, Hacer justicia a la humanidad, México, Fondo de Cultura Económica, 2012.

Riquelme Tapia, Catalina Daniela \& Samaniego Sastre, Mario, "Pueblos indígenas. Reconocimiento y tensiones político-normativas al interior del espacio público en Chile, 1990-2010” en Estudios políticos, 59 (2020), pp. 46-73.

Sarmiento, Manuel, "Cerro Matoso: una historia de fraudes contra el país" en Manuel Sarmiento concejal de Bogotá 2020-2023. Ultimo día de modificación 26 de agosto de 2015. https://manuelsarmiento.com/cerromatoso-una-historia-de-fraudes-contra-el-pais/

Sartre, Jean-Paul, Situaciones VIII: Alrededor del 68. Buenos Aires, Losada, 1973.

Sartre, Jean-Paul, El ser y la nada: ensayo de ontología fenomenológica, Madrid, Alianza editorial, 1989.

Schmitt, Carl, "La relación entre los conceptos «Guerra»y «Enemigo»" [en Héctor Orestes coord. y Angelika Scherp trad.: Carl Schmitt, Teólogo de la Política, 2001], pp. 147-154

Stanton, Timothy, "Hobbes and Schmitt" en History of European Ideas, 2 -37 (2011), p. 64.

Torres Ramis, Luis Alfonso, El "otro" como sujeto y no como objeto: aclaraciones sobre el concepto del otro en El ser y la nada de Jean-Paul Sartre, Master's Thesis Universidad Nacional Mayor de San Marcos, 2018.

Verdú, Vicente, Yo y tú, objetos de lujo: el personismo: la primera revolución cultural del siglo XXI, Barcelona, Debate Editorial, 2006.

Žižek, Slavoj, Trouble in paradise: From the end of history to the end of capitalism. Reino Unido, Melville House, 2015.

Žižek, Slavoj, Against the double blackmail: Refugees, terror and other troubles with the neighbours, Reino Unido, Penguin, 2016.

Žižek, Slavoj, Pandemia. La COVID-19 estremece al mundo, Barcelona, Anagrama, 2020.

El País.Com. España se sitúa ya a la cola de la UE en las concesiones de asilo. Madrid: El País.com. (04/02/2020). Recuperado de https://elpais.com/ politica/2020/02/04/actualidad/1580821771_393934.html

Eurostat Statistics Explained. (2019). Estadísticas de asilo. Recuperado de https://ec.europa.eu/eurostat/statistics-explained/pdfscache/62527.pdf 
Parlamento Europeo, ¿Es Europa hospitalaria? Recuperado de: https://www. europarl.europa.eu/infographic/welcoming-europe/index es.html\#filter= , 2019. (último acceso: 10.05.2021).

Pogge, Thomas, "Injusticia y deberes frente a los refugiados"[en Johnny Antonio Dávila, ed y trad.: Moral, justicia y derechos humanos, Medellín, Editorial Universidad Pontificia Bolivariana, 2017], pp.: 119-152

Lafont, Cristina, Democracy without shortcuts: A participatory conception of deliberative democracy. Oxford University Press, 2019. 